\title{
Research article \\ Differential expression of the angiogenic Tie receptor family in arthritic and normal synovial tissue
}

\author{
Shiva Shahrara ${ }^{1}$, Michael V Volin ${ }^{1}$, Matthew A Connors ${ }^{1}$, G Kenneth Haines ${ }^{2}$ and Alisa E Koch ${ }^{1,3}$
}

${ }^{1}$ Department of Medicine, Northwestern University Medical School, IL, USA

${ }^{2}$ Department of Pathology, Northwestern University Medical School, IL, USA

${ }^{3}$ Veterans Administration, Chicago Health Care System, Lakeside Division, Chicago, IL, USA

Correspondence: Alisa E Koch, MD, Northwestern University Medical School, Department of Medicine, Section of Rheumatology, 303 East Chicago Avenue, Ward Building 3-315, Chicago, Illinois 60611, USA. Tel: +1 312503 1963; fax: +1 312503 0994; e-mail: ae-koch@northwestern.edu

\begin{abstract}
Angiopoietins (Ang) are vascular endothelial cell-specific growth factors that play important roles principally during the later stages of angiogenesis. We have compared the distribution of the receptor tyrosine kinase (Tie) and the Ang ligands in synovial tissues from normal subjects and those with rheumatoid arthritis (RA) and osteoarthritis (OA).

Immunohistochemical analysis was used to determine the expression of Ang-1, Ang-2, Tie1 and Tie2 in synovial tissue of normal subjects and those with RA and OA. Ang-1, Ang-2, Tie1 and Tie2 mRNA and protein expression were quantified in synovial tissues and RA synovial tissue fibroblasts with real-time reverse transcription polymerase chain reaction and western blot analysis.

In RA, Ang-1 positive immunostaining on lining cells, macrophages and endothelial cells was significantly higher than in OA and normal synovial tissue. The expression pattern of Ang-2 in synovial tissue was similar in RA and OA, whereas the Ang-2 expression was low in normal tissue. Synovial tissue from subjects with RA and OA showed a significant upregulation of Tie1 on lining cells, macrophages and endothelial cells compared to that from normal subjects. Tie2 was significantly upregulated in the RA and OA synovial tissue lining cells, macrophages and smooth muscle cells compared to normal synovial tissue. Generally Ang-1, Ang-2, Tie1 and Tie2 mRNA levels were higher in RA synovial tissue compared to normal and OA synovial tissues, and RA synovial tissue fibroblasts. Western blot analysis also demonstrated greater Tie1 and Tie2 protein expression in RA and OA synovial tissue compared to RA synovial tissue fibroblasts. In conclusion, the dominance of Ang-1 mRNA and protein expression over Ang-2 is in agreement with an active neovascularization in RA synovial tissue.
\end{abstract}

Keywords: angiopoietin, mRNA, rheumatoid arthritis, Tie receptor expression

\section{Introduction}

Rheumatoid arthritis (RA) is characterized by synovial tissue leukocyte infiltration and angiogenesis [1]. The neovascularization process in RA is dependent on the balance between angiogenic mediators and inhibitors. The angio- genic mediators include growth factors, cytokines, chemokines, adhesion receptors and proteolytic enzymes [2]. These factors, which are released by endothelial cells and macrophages, have been shown to play an important role in the pathogenesis of RA [2].

Ang = angiopoietin; BSA = bovine serum albumin; FBS = fetal bovine serum; HMVEC = human microvascular endothelial cell; OA = osteoarthritis; $\mathrm{PCR}=$ polymerase chain reaction; $\mathrm{RA}=$ rheumatoid arthritis; $\mathrm{RT}-\mathrm{PCR}=$ reverse transcription polymerase chain reaction, $\mathrm{SE}=$ standard error; Tie $=$ receptor tyrosine kinase; VEGF = vascular endothelial growth factor. 
Tie receptors constitute a family of endothelial tyrosine kinase receptors $[3,4]$. There are two members in this receptor family, termed Tie1 and Tie2 (also known as Tek). Tie1 is an orphan receptor, whereas the ligands of Tie2 receptor have been identified as angiopoietin (Ang)-1 and Ang-2 [5,6]. Ang-1 has been shown to be responsible for recruiting and sustaining periendothelial support cells [7]. It has been reported that Ang-2 disrupts blood vessel formation in the developing embryo by antagonizing Ang-1induced autophosphorylation of Tie2 [6]. Transgenic mouse models of Tie2/Ang-1 result in embryonic lethality due to absence of remodeling and sprouting of blood vessels $[7,8]$. The physiologic roles of the Tie2 receptor and its ligands are limited to angiogenic processes that occur subsequently to the earlier vasculogenic and angiogenic actions of vascular endothelial growth factor (VEGF) and its receptors [7]. VEGF and the Tie family orchestrate optimal blood vessel formation $[9,10]$.

Little is known about the role of Tie receptors and the ligands Ang-1 and Ang-2 in RA synovial tissue. To determine which of these angiogenic factors may play a role in RA, we investigated both the distribution and the levels of mRNA for Tie1, Tie2, Ang-1 and Ang-2 in synovial tissue obtained from RA patients, compared with that from subjects with osteoarthritis $(\mathrm{OA})$ and normal tissues.

\section{Materials and methods}

The patient population details and the methods used for microscopic analysis and statistical analysis are described in the supplementary material.

\section{Antibodies and immunohistochemistry}

Synovial tissues $(4 \mu \mathrm{m})$ were fixed in cold acetone for 20 minutes. Endogenous peroxidase was quenched by treatment with $3 \% \mathrm{H}_{2} \mathrm{O}_{2}$ for 5 minutes. Synovial tissues were pretreated with either $3 \%$ horse or goat serum for one hour at $37^{\circ} \mathrm{C}$ before application of primary antibody. Indirect immunoperoxidase staining was performed at $37^{\circ} \mathrm{C}$ for one hour using Vector Elite ABC kits (Vector, Burlingame, CA, USA) and diaminobenzidine (Kirkegaard and Perry, Gaitherburg, MD, USA) as a chromogen $[11,12]$. The polyclonal antibodies, goat antihuman Ang-1 and Ang-2, and rabbit antihuman Tie1 and Tie2, were purchased from Santa Cruz Biotechnology (Santa Cruz, CA, USA). Additionally, goat antihuman Tie1 and Tie2 antibodies were purchased from R\&D Systems (Minneapolis, MN, USA). Antibodies did not cross-react with other members of the Tie family.

Macrophage identity was confirmed by reactivity of cells with the mouse antihuman mAb, CD11c (Becton Dickinson, Mountain View, CA, USA). Rabbit antihuman von Willebrand factor (Dako, Carpinteria, CA, USA) was used to identify endothelium. Isotype-specific $\lg G$ was used as a negative control.

\section{Cell culture, RNA quantification and western blot analysis}

Cell culture, RNA purification, reverse transcription, standard dilution preparation, real-time reverse transcription polymerase chain reaction (RT-PCR) quantification (TaqMan) and western blot analysis are detailed in the supplementary material.

\section{Results \\ Ang-1}

Ang-1, was expressed on synovial lining cells in RA patients $(33 \%)$ to a significantly higher degree than in OA $(10 \%)$ and normal $(1 \%)$ cells $(P<0.05)$ (Fig. 1). Ang-1 staining on macrophages was also significantly higher in RA (39\%) compared to OA (10\%) and normal cells $(0 \%)$ $(P<0.05)$. The Ang-1 staining present on vascular endothelium was upregulated in RA (86\%) compared to OA $(8 \%)$ and normal synovial tissues (6\%). The inflammatory and vascularity scores were higher in RA synovial tissue in comparison to $\mathrm{OA}$ and normal. In accordance with the staining data, RA synovial tissue demonstrated significantly higher Ang-1 mRNA expression compared to $\mathrm{OA}$ and normal tissues. Ang-1 mRNA expression was not detected in RA fibroblasts (Fig. 1).

\section{Ang-2}

The expression of Ang-2 was detected on synovial lining cells, macrophages and vascular endothelium (Fig. 2). The data demonstrate that Ang-2 was expressed on macrophages (30\%) and the vascular endothelium (78\%) in synovial tissue of RA patients more strongly than in the tissue of OA patients (macrophages 11\%, endothelium $66 \%$ ) and normal subjects (macrophages 12\%, endothelium 15\%). Additionally, Ang-2 was detected in the synovial vascular smooth muscle cells (13\%) from RA patients only.

The Ang-2 mRNA expression pattern was similar to Ang-2 immunostaining on vascular endothelium. The Ang-2 mRNA expression in RA synovial tissue was similar to that from OA patients, and both were significantly higher than normal. Interestingly, in RA synovial tissue fibroblasts, Ang2 mRNA was expressed at low levels compared to that found in whole RA, OA or normal synovial tissue (Fig. 2).

\section{Tie1}

Tie1 expression was found to be significantly higher in RA and OA synovial tissue lining cells (RA 79\%, OA 81\%) and macrophages (RA 69\%, OA 66\%) compared to normal synovial tissue (lining cells 24\%, macrophages 22\%) using antibodies from Santa Cruz Biotechnology (Fig. 3). Tie1 immunostaining on endothelial cells was significantly higher in RA synovial tissue (75\%) in comparison to OA (3\%) and normal (9\%) synovial tissue. The Tie1 positive immunostaining on vascular smooth muscle cells was similar in all test groups (RA 74\%, OA 78\%, normal 


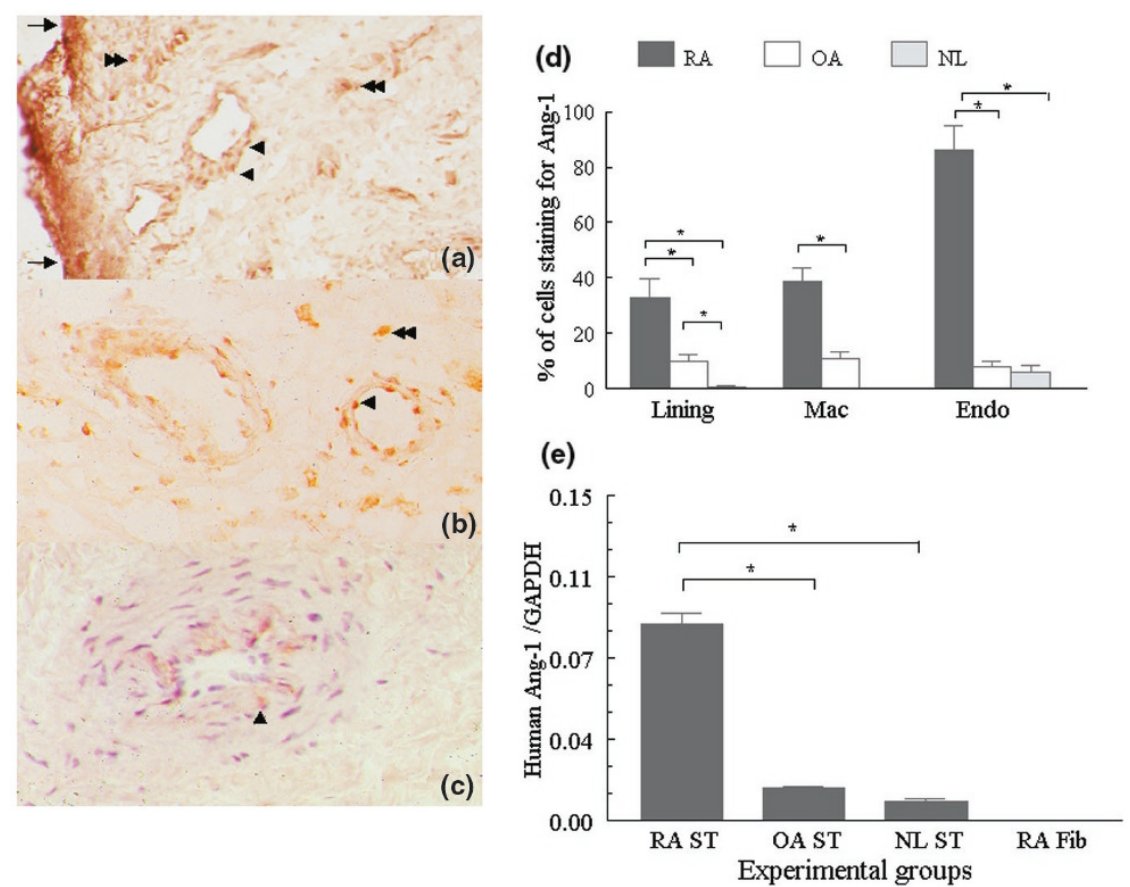

\begin{abstract}
Expression pattern of angiopoietin-1 (Ang-1) in synovial tissues. The arrows denote the lining cell layer, the double arrowhead denotes subsynovial macrophages and the single arrowhead denotes vascular endothelium. The immunohistochemistry was performed with a goat antihuman Ang-1 polyclonal antibody from Santa Cruz Biotechnology (Santa Cruz, CA, USA). (a) Synovial tissue from a patient with rheumatoid arthritis showing positive staining for Ang-1. (b) Positive staining in osteoarthritis synovial tissue. (c) Ang-1 staining is absent in normal synovial tissue.

(a), (b) and (c) Original magnification $\times 226$. (d) Immunohistochemistry of synovial tissues from normal (NL) subjects $(n=5)$ and those with rheumatoid arthritis (RA) $(n=9)$ and osteoarthritis (OA) $(n=8)$. The bars represent mean \pm SE. (e) Ang-1 mRNA levels in synovial tissue (ST) and RA fibroblasts (Fib) were quantified using real-time reverse transcription-PCR and normalized to glyceraldehyde-3-phosphate dehydrogenase $(\mathrm{GAPDH})$. Bars represent the mean $\pm \mathrm{SE}(n=3)$. Lining, synovial tissue lining cell layer; Mac, subsynovial macrophages; Endo, vascular endothelium. ${ }^{*} P<0.05$.
\end{abstract}

71\%). Additionally, all disease groups demonstrated minimal percentages of Tie1 cell staining on synovial tissue lymphocytes (RA 1\%, OA 2\%, normal 6\%) and fibroblasts (RA 18\%, OA 18\%, normal 30\%).

Immunohistochemistry studies using the goat antihuman Tie1 antibody purchased from R\&D Systems showed predominantly endothelial cell staining, and minimal staining on macrophages and fibroblasts. Tie1 mRNA expression was significantly higher in RA synovial tissue compared to OA synovial tissue (threefold), normal synovial tissue (9.5-fold) and RA synovial tissue fibroblasts (sixfold). Western blot analysis also confirmed the same pattern of expression.

\section{Tie2}

Tie2 was significantly upregulated in RA and OA synovial tissue lining cells (RA 71\%, OA 68\%), macrophages (RA 71\%, OA 72\%) and smooth muscle cells (RA 71\%, OA 66\%) compared to normal synovial tissue $(P<0.05)$ using the Santa Cruz antibodies (Fig. 4). Endothelial cells showed relatively high Tie 2 positive staining in all disease groups (RA 71\%, OA 66\%, normal 49\%). Only synovial tissue from RA patients demonstrated positive staining for Tie2 on lymphocytes. RA and OA patients had similar patterns of Ang-2 (on cell lining and endothelial cells), Tie1 (on lining cells, macrophages, smooth muscle cells, lymphocytes and fibroblasts) and Tie2 (on lining cells, macrophages, endothelial cells and vascular smooth muscle cells) expression on various synovial tissue components. The anti-Tie2 antibody from R\&D Systems demonstrated positive staining mainly on endothelial cells and minimal staining on macrophages and fibroblasts. Tie2 mRNA levels were significantly higher in RA synovial tissue compared to OA synovial tissue (1.9-fold), normal synovial tissue (fourfold) and RA synovial tissue fibroblasts (9.6-fold). Tie2 protein expression by western blotting followed the same pattern as the mRNA expression (Fig. 4).

\section{Discussion}

The Tie receptors and the ligands Ang-1 and Ang-2 appear to be involved in the later stages of vessel growth and remodeling $[8,13]$. Transgenic mice with gene deletions [7,8,13] or overexpression of Ang-2 [6] exhibit early 


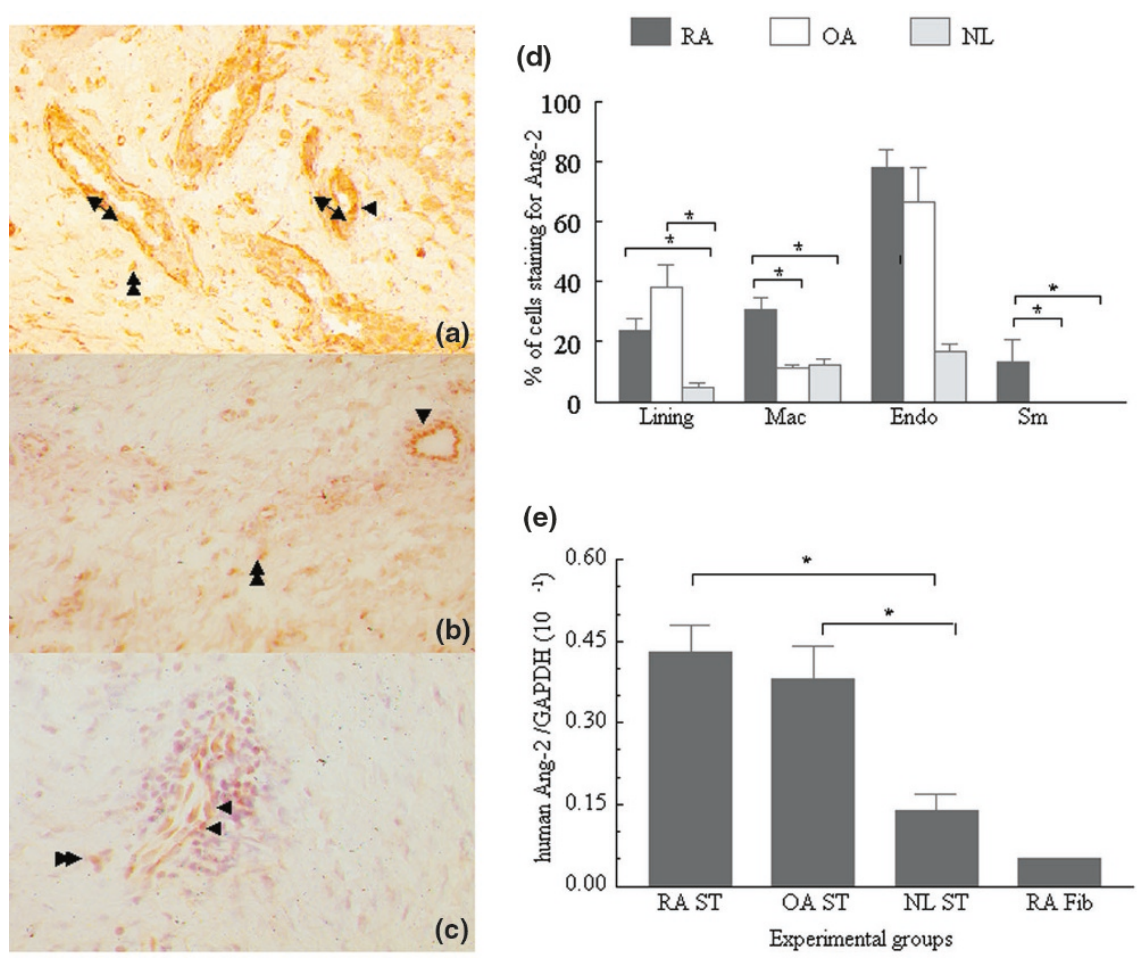

Expression pattern of angiopoietin-2 (Ang-2) mRNA and protein in synovial tissues. The double arrowhead denotes subsynovial macrophages, the single arrowhead denotes vascular endothelium and the double headed arrows denote vascular smooth muscle cells. The immunohistochemistry was performed with a goat antihuman Ang-2 polyclonal antibody from Santa Cruz Biotechnology (Santa Cruz, CA, USA). (a) Synovial tissue from a patient with rheumatoid arthritis showing positive staining for Ang-2. (b) Positive staining for Ang-2 in osteoarthritis synovial tissue. (c) Ang-2 staining is absent in normal synovial tissue. (a), (b) and (c) Original magnification $\times 226$. (d) Immunohistochemistry of synovial tissues from normal (NL) subjects $(n=7)$ and those with rheumatoid arthritis (RA) $(n=11)$ and osteoarthritis (OA) $(n=12)$. The bars represent mean \pm SE. (e) Ang-2 mRNA levels in synovial tissue (ST) and RA fibroblasts (Fib) were quantified using real-time reverse transcription-PCR and normalized to glyceraldehyde-3-phosphate dehydrogenase (GAPDH). Bars represent the mean $\pm \mathrm{SE}(n=3)$. Lining, synovial tissue lining cell layer; Mac, subsynovial macrophages; Endo, vascular endothelium; Sm, vascular smooth muscle cells. ${ }^{\star} P<0.05$.

embryonic lethality secondary to defects in the developing vasculature.

Ang-1 was more highly expressed in synovial tissue from RA patients than in either OA or normal synovial tissues; expression in OA tissue was similar to normal. Positive cells included lining cells, macrophages and endothelial cells. In RA, Ang-1 was most upregulated on endothelial cells. The results obtained from RT-PCR analysis confirmed that RA synovial tissue had significantly higher Ang1 mRNA expression than OA and normal synovial tissue. Hence, no Ang-1 mRNA expression was detected in RA fibroblasts (Fig. 1). The Tie receptor family is known to be expressed on endothelial cells [5]. Otani et al [14] reported Ang-1 and Ang-2 positive staining on macrophages and endothelial cells in choroidal neovascular membranes. Macrophages are key angiogenesis effector cells that produce a number of growth factor stimulators and inhibitors, proteolytic enzymes and cytokines that can activate one or more steps in the angiogenesis cascade
[15-17]. Recent studies have shown that angiopoietins promote postnatal neovascularization by potentiating angiogenic cytokines such as VEGF $[9,10]$.

In situ hybridization and immunohistochemical analyses of RA synovial biopsies revealed that VEGF mRNA and protein localized to subsynovial macrophages, lining cells, vascular smooth muscle cells and fibroblasts within the pannus, which are the putative target of this cytokine $[18,19]$. The localization of Ang-1 is similar to that of VEGF, which further supports the crucial role of the interaction between these two pathways. Ang-1 modulates VEGF-stimulated reorganization of endothelial cells and promotes vascular network maturation $[9,20]$. Additionally, both Ang-1 and VEGF are chemotactic and are involved in recruiting endothelial cells to initiate and accelerate endothelialization of blood vessels $[21,22]$.

We detected Ang-2 immunopositive cells in synovial lining, macrophages and vascular endothelium. Vascular 

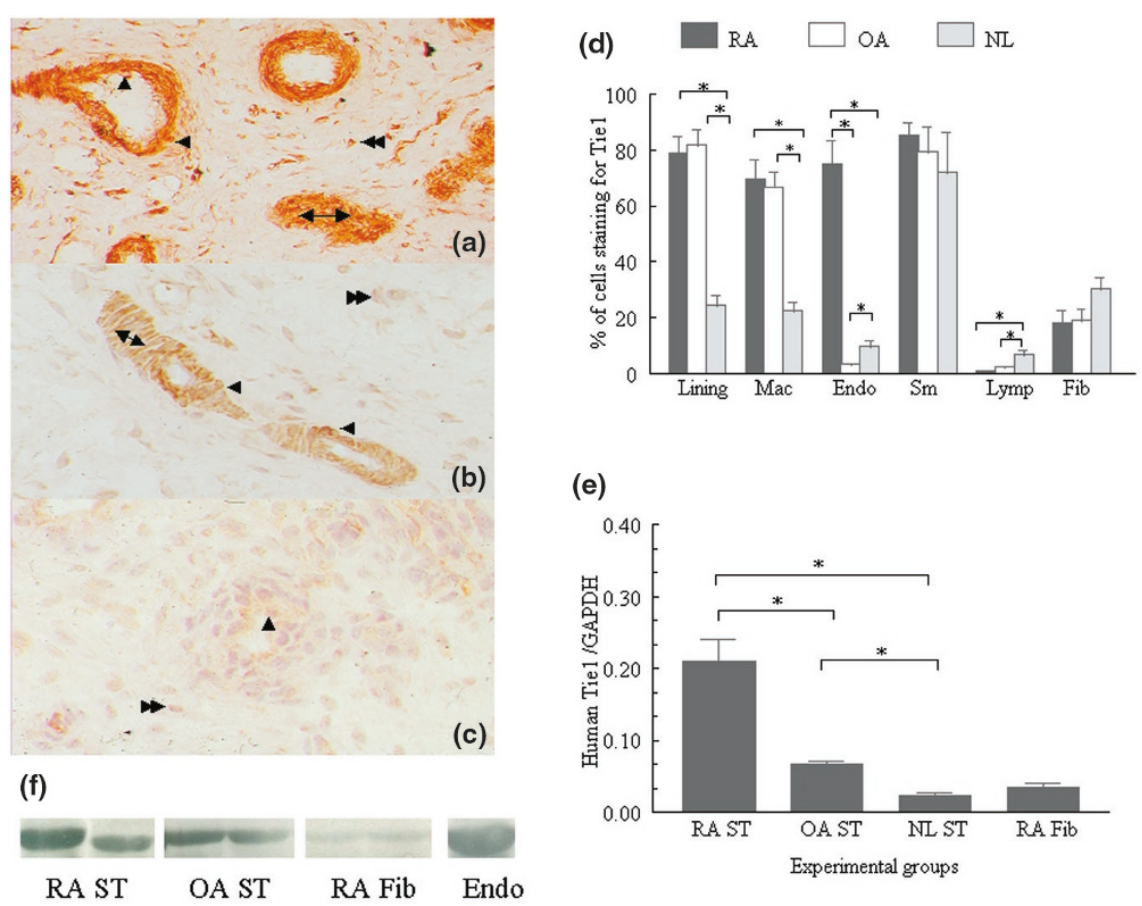

(e)

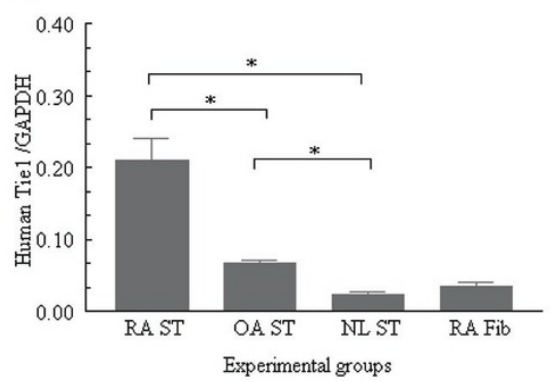

Expression pattern of Tie1 in synovial tissues. The double arrowhead denotes subsynovial macrophages, the single arrowhead denotes vascular endothelium and the double headed arrows denote vascular smooth muscle cells. The immunohistochemistry was performed with a rabbit antihuman Tie1 polyclonal antibody from Santa Cruz Biotechnology (Santa Cruz, CA, USA). (a) Synovial tissue from a patient with rheumatoid arthritis showing positive staining for Tie1. (b) Positive staining for Tie1 in osteoarthritis synovial tissue. (c) Tie1 staining is absent in normal synovial tissue. (a), (b) and (c) Original magnification $\times 212$. (d) Immunohistochemistry of synovial tissues from normal (NL) subjects $(n=9)$ and those with rheumatoid arthritis (RA) $(n=12)$ and osteoarthritis (OA) $(n=11)$. The bars represent mean \pm SE. (e) Tie1 mRNA levels in synovial tissue (ST) and RA fibroblasts (Fib) were quantified using real-time reverse transcription-PCR and normalized to glyceraldehyde-3-phosphate dehydrogenase $(\mathrm{GAPDH})$. Bars represent the mean $\pm \mathrm{SE}(n=3)$. ( $\mathrm{f})$ Western blot analysis of Tie1 in synovial tissues from RA, OA, RA fibroblasts and human microvascular endothelial cells (Endo) using the goat antihuman antibody from R\&D Systems (Minneapolis, MN, USA). Lining, synovial tissue lining cell layer; Mac, subsynovial macrophages; Endo, vascular endothelium; Sm, vascular smooth muscle cells; Lymph, lymphocytes. ${ }^{\star} P<0.05$.

smooth muscle immunostaining was found only in RA. In agreement with our finding, it has been reported that primary cultured macrophages and precursor macrophage cell lines mainly express Ang-2 mRNA [23]. In contrast to Ang-1, Ang-2 was distributed in a similar pattern in RA and OA compared to normal synovial tissues (Fig. 2). The dominance of Ang-2 over Ang-1 mRNA and protein in OA synovial tissue are in agreement with the inactive VEGF receptor 1 pathway (angiogenic pathway) in OA [24]. The Ang-2 mRNA expression pattern correlates with the Ang-2 immunostaining detected on endothelial cells. In RA synovial tissue, Ang-2 showed a lower percentage of staining in all the cell types compared to Ang-1. Low Ang-2 mRNA expression was also detected on RA fibroblasts. Interestingly Ang-2 acts as an agonist for Tie2 receptors expressed on fibroblasts [6]. Since the neovascularization process is dependent on the dominance of angiogenic mediators over inhibitors, the higher Ang-1 mRNA and protein expression compared to Ang-2 in RA synovial tissue is of importance. It has been shown that increasing amounts of Ang-2 can block the chemotactic activity of Ang-1 in endothelial cells [21]. Ang-2 alone did not stimulate corneal neovascularization, but the combination of Ang-2 and VEGF resulted in longer vessels with greater circumferential extent than those seen with VEGF alone [9]. This suggests that Ang-2 expression in the absence of VEGF leads to vessel regression, whereas expression of Ang-2 in the presence of VEGF potentiates angiogenesis.

Using the Santa Cruz Biotechnology antibody, Tie1 expression was detected on all cell components examined, including a percentage of synovial lining cells, macrophages and smooth muscle cells in RA and OA. Synovial tissues from normal subjects, and those with OA, had considerably lower positive immunostaining on endothelial cells compared to RA tissues. Immunohistochemical analysis performed with anti-Tie1 from R\&D Systems in synovial tissues supports its expression mainly on endothelial cells. However, western blot analysis for Tie1 also performed with an antibody from R\&D Systems, 

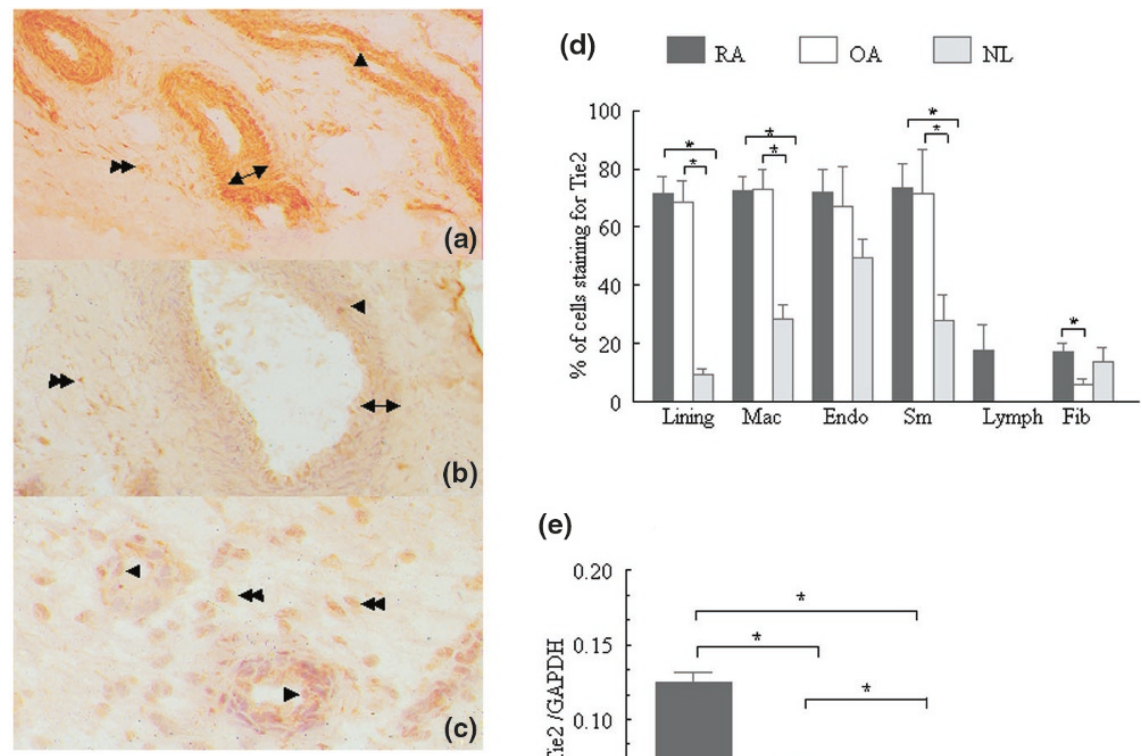

(b)

(f)

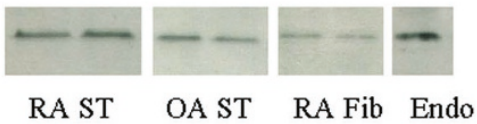

(e)

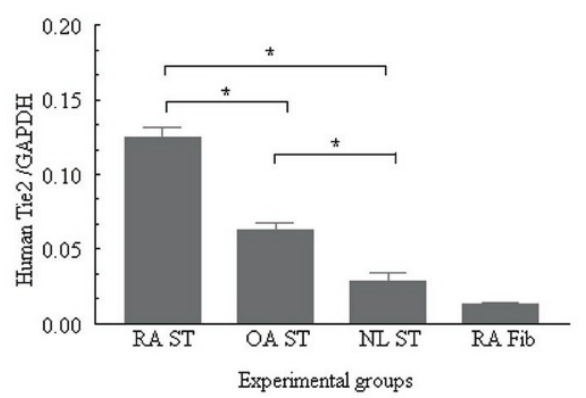

Expression patterns of Tie2 mRNA and protein. The double arrowhead denotes subsynovial macrophages, the single arrowhead denotes vascular endothelium and the double headed arrows denote vascular smooth muscle cells. The immunohistochemistry was performed with a rabbit antihuman Tie2 polyclonal antibody from Santa Cruz Biotechnology (Santa Cruz, CA, USA). (a) Synovial tissue from a patient with rheumatoid arthritis showing positive staining for Tie2. (b) Positive staining for Tie2 in osteoarthritis synovial tissue. (c) Tie2 staining is absent in normal synovial tissue. (a), (b) and (c) Original magnification $\times 200$. (d) Immunohistochemistry of synovial tissues from normal (NL) subjects $(n=11)$ and those with rheumatoid arthritis (RA) $(n=15)$ and osteoarthritis (OA) $(n=11)$. The bars represent mean \pm SE. (e) Tie2 mRNA levels in synovial tissue (ST) and RA fibroblasts (Fib) were quantified using real-time reverse transcription-PCR and normalized to glyceraldehyde-3phosphate dehydrogenase (GAPDH). Bars represent the mean \pm SE $(n=3)$. (f) Western blot analysis of Tie2 in synovial tissues from RA, OA, RA fibroblasts and human microvascular endothelial cells (Endo) using the goat antihuman antibody from R\&D Systems (Minneapolis, MN, USA). Lining, synovial tissue lining cell layer; Mac, subsynovial macrophages; Endo, vascular endothelium; Sm, vascular smooth muscle cells; Lymph, lymphocytes. ${ }^{*} P<0.05$.

showed higher relative abundance of Tie1 in whole RA and OA synovial tissue homogenates compared to RA fibroblasts (Fig. 3). In accordance with the protein data, the mRNA levels of Tie1 in RA synovial tissue were upregulated compared to OA synovial tissue, normal synovial tissue and RA fibroblasts. Since the ligand for the Tie1 receptor is not known, it is difficult to speculate if there is any correlation between this receptor and Tie2 and its ligands. In agreement with previous studies, the Tie1 receptor was detected on vascular endothelial cells $[4,25]$ and recently on synovial lining cells [26]. It has been shown that tumor necrosis factor- $\alpha$ and VEGF activate membrane-associated metalloproteinases that release soluble Tie1 from the cell surface of endothelial cells and thereby decrease membrane-bound Tie1 expression [27]. The upregulation of Tie1 mRNA and protein expression in RA is not consistent with these findings and this may be due to the fact that the inflammatory milieu in RA synovial tissue is far more complex than the in vitro system.
Using the Santa Cruz Biotechnology antibody we showed that Tie2 expression was significantly upregulated both in RA and OA synovial tissue lining cells, macrophages, endothelial cells and vascular smooth muscle compared to normal synovial tissue. In accordance with Otani et al. [14] and Uchida et al. [26] we detected Tie2 immunostaining on endothelial cells and fibroblasts in all disease groups. Tie2 immunostaining using antibody from R\&D Systems confirmed the expression of this antigen mainly on endothelial cells. Tie 2 mRNA and protein expression followed the same pattern of expression as Tie1. There are some possible reasons why the immunohistochemistry studies performed with Santa Cruz Biotechnology/R\&D Systems antibodies differ. The Santa Cruz Biotechnology antibodies detected epitopes on the carboxy terminus whereas the R\&D Systems antibodies recognized the extracelluar domain ( $\mathrm{N}$ terminus or the ligand binding domain) of Tie1 and Tie2. There is also some variability between individual RA patient samples, however, we 
attempted to use the same RA patient samples in performing immunohistochemistry with the two different antibodies. Additionally, the results obtained from the RT-PCR and western blot analysis confirm our findings.

\section{Conclusion}

It is noteworthy that the activating ligand, Ang-1 is exclusively higher than Ang-2 at the mRNA and protein levels in RA synovial tissue compared to that from patients with OA and normal subjects. Hypothetically, in RA synovial tissue the dominating Ang-1 induces the Tie2 pathway, whereas in normal synovial tissue higher Ang-2 presence blocks Ang-1 binding to Tie2 and inhibits its autophosphorylation.

In conclusion, the dominance of Ang-1 over Ang-2 expression favors active neovascularization in RA synovial tissue. Multiple pathways are probably required to regulate angiogenesis. It may be that the inhibition of the VEGF and Tie2 pathways might be an effective therapeutic modality in RA.

\section{Acknowledgements}

This work was supported by NIH Grants HL58695, Al40987, the Gallagher Professorship for Arthritis Research, and funds from the Veteran's Administration Research Service.

\section{References}

1. Koch AE: Angiogenesis: implications for rheumatoid arthritis. Arthritis Rheum 1998, 41:951-962.

2. Szekanecz Z, Szegedi G, Koch AE: Angiogenesis in rheumatoid arthritis: pathogenic and clinical significance. J Invest Med 1998, 46:27-41.

3. Dumont DJ, Yamaguchi TP, Conlon RA, Rossant J, Breitman ML: tek, a novel tyrosine kinase gene located on mouse chromosome 4, is expressed in endothelial cells and their presumptive precursors. Oncogene 1992, 7:1471-1480.

4. Partanen J, Armstrong $E$, Makela TP, Korhonen J, Sandberg $M$ Renkonen R, Knuutila S, Huebner K, Alitalo K: A novel endothelial cell surface receptor tyrosine kinase with extracellular epidermal growth factor homology domains. Mol Cell Biol 1992, 12:1698-1707.

5. Davis S, Aldrich TH, Jones PF, Acheson A, Compton DL, Jain V, Ryan TE, Bruno J, Radziejewski C, Maisonpierre PC, Yancopolous GD: Isolation of Angiopoietin-1, a ligand for the TIE2 receptor, by Secretion-Trap Expression Cloning. Cell 1996, 87:1161-1169.

6. Maisonpierre PC, Suri C, Jones PF, Bartunkova S, Wiegand SJ, Radziejewski C, Compton D, McClain J, Aldrich TH, Papadopoulos N, Daly TJ, Davis S, Sato TN, Yancopoulos GD: Angiopoietin2, a natural antagonist for Tie2 that disrupts in vivo angiogenesis. Science 1997, 277:55-60.

7. Suri C, Jones PF, Patan S, Bartunkova S, Maisonpierre PC, Davis $\mathrm{S}$, Sato TN, Yancopoulos GD: Requisite role of angiopoietin-1, a ligand for the Tie2 receptor, during embryonic angiogenesis. Cell 1996, 87:1171-1180.

8. Sato TN, Tozawa Y, Deutsch U, Wolburg-Buchholz K, Fujiwara Y, Gendron-Maguire M, Gridley T, Wolburg H, Risau W, Qin Y: Distinct roles of the receptor tyrosine kinases Tie-1 and Tie-2 in blood vessel formation. Nature 1995, 376:70-74.

9. Asahara T, Chen D, Takahashi T, Fujikawa K, Kearney M, Magner M, Yancopoulos GD, Isner JM: Tie2 receptor ligands, angiopoietin-1 and angiopoietin-2, modulate VEGF-induced postnatal neovascularization. Circ Res 1998, 83:233-240.

10. Hackett SF, Ozaki H, Strauss RW, Wahlin K, Suri C, Maisonpierre P, Yancopoulos G, Campochiaro PA: Angiopoietin 2 expression in the retina: upregulation during physiologic and pathologic neovascularization. J Cell Physio/ 2000, 184:275-284.

11. Szekanecz Z, Haines GK, Harlow LA, Shah MR, Fong TW, Fu R, Lin SJ-W, Rayan G, Koch AE: Increased synovial expression of TGF- $\beta$ receptor endoglin and TGF- $\beta 1$ in rheumatoid arthritis. Clin Immunol Immunopathol 1995, 76:187-194.
12. Halloran MM, Szekanecz Z, Barquin N, Haines GK, Koch AE: Cellular adhesion molecules in rat adjuvant arthritis. Arthritis Rheum 1996, 39:810-819.

13. Dumont DJ, Gradwohl G, Fong GH, Puri MC, Gertsenstein M, Auerbach A, Breitman ML: Dominant-negative and targeted null mutations in the endothelial receptor tyrosine kinase, tek, reveal a critical role in vasculogenesis of the embryo. Genes Dev 1994, 8:1897-1909.

14. Otani A, Takagi $H$, Oh $H$, Koyama S, Matsumura M, Honda $Y$ : Expressions of angiopoietins and Tie2 in human choroidal neovascular membranes. Invest Ophthalmol Vis Sci 1999, 40: 1912-1920.

15. Koch AE, Polverini PJ, Kunkel SL, Harlow LA, DiPietro LA, Elner VM, Elner SG, Strieter RM: Interleukin-8 as a macrophagederived mediator of angiogenesis. Science 1992, 258:17981801.

16. Koch AE, Kunkel SL, Harlow LA, Mazarakis DD, Haines GK, Burdick MD, Pope RM, Walz A, Strieter RM: Epithelial neutrophil activating peptide-78: a novel chemotactic cytokine for neutrophils in arthritis. J Clin Invest 1994, 94:1012-1018.

17. Polverini PJ: Role of the macrophage in angiogenesis-dependent diseases. EXS 1997, 79:11-28.

18. Fava RA, Olsen NJ, Spencer-Green G, Yeo KT, Yeo TK, Berse B Jackman RW, Senger DR, Dvorak HF, Brown LF: Vascular permeability factor/endothelial growth factor (VPF/VEGF): accumulation and expression in human synovial fluids and rheumatoid synovial tissue. J Exp Med 1994, 180:341-346.

19. Koch AE, Harlow LA, Haines GK, Amento EP, Unemori EN, Wong WL, Pope RM, Ferrara N: Vascular endothelial growth factor. A cytokine modulating endothelial function in rheumatoid arthritis. J Immunol 1994, 152:4149-4156.

20. Koblizek TI, Weiss C, Yancopoulos GD, Deutsch U, Risau W: Angiopoietin-1 induces sprouting angiogenesis in vitro. Curr Biol 1998, 8:529-532.

21. Witzenbichler $B$, Maisonpierre PC, Jones $P$, Yancopoulos GD, Isner JM: Chemotactic properties of angiopoietin-1 and -2 ligands for the endothelial-specific receptor tyrosine kinase Tie2. J Biol Chem 1998, 273:18514-18521.

22. Tsurumi $Y$, Murohara $T$, Krasinski $K$, Chen $D$, Witzenbichler $B$ Kearney M, Couffinhal T, Isner JM: Reciprocal relation between VEGF and NO in the regulation of endothelial integrity. Nat Med 1997, 3:879-886.

23. Kim I, Kim JH, Ryu YS, Jung SH, Nah JJ, Koh GY: Characterization and expression of a novel alternatively spliced human angiopoietin-2. J Biol Chem 2000, 275:18550-18556.

24. Giatromanolaki A, Sivridis E, Athanassou N, Zois E, Thorpe PE, Brekken RA, Gatter KC, Harris AL, Koukourakis IM, Koukourakis MI: The angiogenic pathway "vascular endothelial growth factor/flk-1(KDR)-receptor" in rheumatoid arthritis and osteoarthritis. J Pathol 2001, 194:101-108.

25. Sato TN, Qin Y, Kozak CA, Audus KL: Tie-1 and tie-2 define another class of putative receptor tyrosine kinase genes expressed in early embryonic vascular system. Proc Natl Acad Sci USA 1993, 90:9355-9358.

26. Uchida T, Nakashima M, Hirota $Y$, Miyazaki Y, Tsukazaki T, Shindo $\mathrm{H}$ : Immunohistochemical localisation of protein tyrosine kinase receptors Tie-1 and Tie-2 in synovial tissue of rheumatoid arthritis: correlation with angiogenesis and synovial proliferation. Ann Rheum Dis 2000, 59:607-614.

27. Yabkowitz R, Meyer S, Black T, Elliott G, Merewether LA, Yamane HK: Inflammatory cytokines and vascular endothelial growth factor stimulate the release of soluble tie receptor from human endothelial cells via metalloprotease activation. Blood 1999, 93:1969-1979.

28. Altman R, Asch E, Bloch D, Bole G, Borenstein D, Brandt K, Christy W, Cooke TD, Greenwald R, Hochberg M, Howell D, Kaplan D, Koopman W, Longley S 3rd, Mankin H, McShane DJ, Medsger TJ, Meenan R, Mikkelsen W, Moskowitz R, Murphy W, Rothschild B, Segal M, Sokoloff L, Wolfe F: Development of criteria for the classification and reporting of osteoarthritis. Classification of osteoarthritis of the knee. Arthritis Rheum 1986, 29:1039-1049.

29. Altman R, Alarcon G, Appelrouth D, Bloch D, Borenstein D, Brandt K, Brown C, Cooke TD, Daniel W, Feldman D, Greenwald R, Hochberg M, Howell D, Ike R, Kapila P, Kaplan D, Koopman W, Marino C, McDonald E, McShane DJ, Medsger TJ, Michel B, Murphy WA, Osial T, Ramsey-Goldman R, Rothschild B, Wolfe F: 
The American College of Rheumatology criteria for the classification and reporting of osteoarthritis of the hip. Arthritis Rheum 1991, 34:505-514.

30. Koch AE, Polverini PJ, Leibovich SJ: Stimulation of neovascularization by human rheumatoid synovial tissue macrophages. Arthritis Rheum 1986, 29:471-479.

31. Chomczynski P, Sacchi N: Single-step method of RNA isolation by acid guanidinium thiocyanate-phenol-chloroform extraction. Anal Biochem 1987, 162:156-159.

32. Endesfelder S, Krahn A, Kreuzer KA, Lass U, Schmidt CA, Jahrmarkt $C$, von MA, Speer A: Elevated p21 mRNA level in skeletal muscle of DMD patients and $\mathrm{mdx}$ mice indicates either an exhausted satellite cell pool or a higher p21 expression in dystrophin-deficient cells per se. J Mol Med 2000, 78: 569-574.

33. Favy DA, Lafarge S, Rio P, Vissac C, Bignon YJ, Bernard-Gallon D: Real-time PCR quantification of full-length and exon 11 spliced BRCA1 transcripts in human breast cancer cell lines. Biochem Biophys Res Commun 2000, 274:73-78.

\section{Supplementary material}

\section{Materials and methods \\ Patient population}

Synovial tissues from patients with RA and OA, undergoing arthroplasty or synovectomy, who fulfilled the criteria set by the American College of Rheumatology were obtained with Institutional Review Board (IRB) consent $[28,29]$. Normal synovial tissues were obtained from fresh autopsies or amputations. Synovial tissues were snap frozen in Optimal Cutting Temperature (OCT) compound (Miles, Elkhart, IN, USA).

\section{Microscopic analysis}

Synovial tissue components including lining cells, macrophages, lymphocytes, fibroblasts, smooth muscle cells and endothelial cells were graded for immunostaining by a frequency of staining scale, scored $0-100 \%$, where $0 \%$ indicates no staining and $100 \%$ indicates that all cells were immunoreactive. Five $400 x$ fields were examined per section by a single pathologist in a blinded study. Selected sections were analyzed by two additional observers.

\section{Statistical analysis}

Data were analyzed using a Kruskal Wallis test. There were 5 to 15 patient samples per group. $P$ values $<0.05$ were considered to be significant.

\section{Cell culture}

Fibroblasts were isolated from synovial tissues that had been minced and digested in a solution of dispase, collagenase and DNase. Synovial tissue fibroblasts were cultured in Roswell Park Memorial Institute (RPMI)-1640 supplemented with $10 \%$ FBS and $1 \%$ penicillin/streptomycin (P/S) and used at passage five or older, at which time they were a homogeneous population of fibroblasts.
Human microvascular endothelial cells (HMVECs) (BioWhittaker, CA, USA) were cultured in endothelial cell growth medium-2 for microvascular cells (BioWhittaker, Walkerville, MD, USA) and were used between passages 3 and 12. Upon confluence, the cells were passaged by brief trypsinisation as previously described [30]. HMVECs were used as positive controls for Tie1 and Tie2 protein expression in western blot analysis.

\section{RNA purification}

Total RNA was prepared from synovial tissue by an acid phenol method according to the procedure described by Chomczynski and Sacchi [31]. RNA $(20 \mu \mathrm{g})$ was digested with five units of DNase in $1 \times$ reverse transcription buffer (Gibco/Life Technologies, Grand Island, NY, USA) containing eight units of RNase inhibitor (Gibco/Life Technologies, Grand Island, NY, USA) for 30 minutes at $37^{\circ} \mathrm{C}$. Sodium acetate $(2 \mathrm{M}, \mathrm{pH} 4.0)$ was added $(10 \%$ of the total volume), and the solution was extracted with one volume each of water-saturated phenol and chloroform (Fisher, Itasca, IL, USA). The RNA was precipitated with ethanol, washed with $75 \%$ ethanol, then air-dried. The pellet was dissolved in water at $1 \mu \mathrm{g} / \mu \mathrm{l}$.

\section{Reverse transcription}

Reverse transcription of RNA was performed using $5 \mu \mathrm{g}$ of RNA in a total volume of $20 \mu \mathrm{l}$. The RNA was reverse transcribed by Superscript II RT (Gibco/Life Technologies, Grand Island, NY, USA) according to manufacturer's specification. After 10 minutes at $25^{\circ} \mathrm{C}$, the enzyme was incubated at $42^{\circ} \mathrm{C}$ for 50 minutes and thereafter inactivated at $70^{\circ} \mathrm{C}$ for 15 minutes. The solution was diluted to $40 \mu \mathrm{l}$. All samples were reverse transcribed simultaneously.

\section{Standard dilution preparation and PCR}

All PCR reactions were performed on an ABI Prism 7700 Sequence Detection System (Perkin Elmer Applied Biosystem, CA, USA). For each PCR run, a master mixture was prepared on ice with $1 \times$ Platinum PCR buffer (Gibco/Life Technologies, Grand Island, NY, USA), $1.5 \mathrm{mM} \mathrm{MgCl}_{2}$, $0.2 \mathrm{mM}$ of each deoxynucleoside triphosphate, $0.2 \mu \mathrm{M}$ each primer, 2.5 units platinum Taq DNA polymerase (Gibco/Life Technologies, Grand Island, NY, USA). The diluted reverse transcription sample $(3 \mu \mathrm{l})$ was added to 25 $\mu \mathrm{l}$ of the PCR mix. The thermal cycling conditions were 40 cycles of the denaturation step at $95^{\circ} \mathrm{C}$ for 30 seconds, annealing at $60^{\circ} \mathrm{C}$ for one minute and an extention step at $72^{\circ} \mathrm{C}$ for one minute. PCR products were extracted from agarose gels and purified. Serial dilutions of PCR products were then prepared which ranged from $10^{1}$ to $10^{10}$ molecules [32]. The sequence for the designed Tie receptors and ligands are shown in Supplementary Table 1.

Real-time quantitative RT-PCR using the TaqMan system The PCR primer and the TaqMan fluorogenic probe were designed using the Primer Express program v 1.01 (Perkin 
Supplementary Table 1

\begin{tabular}{|c|c|c|c|}
\hline Names & Forward primers & TaqMan probes & Reverse primers \\
\hline Ang-1 & GCC ATT ACC AGT CAG AGG CAG T & CAT GCT AAG AAT TGA GTT AAT & AAT AGG CTC GGT TCC CTT CC \\
\hline Ang-2 & CGC TCG AAT ACG ATG ACT CG & TGC AGA GGC TGC AAG TGC TGG AGA A & CCA CTG AGT GTT GTT TTC CAT GAT \\
\hline Tie1 & GCC ACG TTC TGG CTG GAT & TCA GGC CTC CTC AGC TGT GGC AT & ACT TCA CTT ACG CGG GCA TT \\
\hline Tie2 & GGC AAC TTG ACT TCG GTG CT & ACT TAC ATC CCA GGG AGC AGT ACG TGG TC & GGC CTT GGT GTT GAC TCT AGC T \\
\hline
\end{tabular}

Elmer Applied Biosystem, CA, USA). The TaqMan probe carries a 5' FAM (6-carboxy-fluorescein) reporter dye and a 3' TAMRA (6-carboxy-tetramethyl-rhodamine) quencher dye (Mega Bases, Chicago, IL, USA) The quantity of cDNA of the gene of interest was directly related to the fluorescence detection of FAM after 40 cycles. The amount of cDNA was calculated using a comparative $\mathrm{C}_{\mathrm{T}}$ method and the standard curve method [33] according to Perkin Elmer ABI PRISM 7700 User Bulletin No. 2, 1997. The calibration curves showed a strong linear correlation, with correlation coefficients between 0.96 and 0.99. In both methods, the estimated amount of the gene of interest was normalized by the amount of glyceraldehyde-3-phosphate dehydrogenase to compensate for variations in quantity and for differences in reverse transcription efficiency.

Briefly, $3 \mu \mathrm{l}$ of the cDNA was in a reaction of $25 \mu \mathrm{l}$ that contained final concentrations of $1 \times$ Platinum PCR buffer (Gibco/Life Technologies, Grand Island, NY, USA), $3.5 \mathrm{mM} \mathrm{MgCl} 2,200 \mu \mathrm{M}$ dNTP, $500 \mathrm{nM}$ each primer (Mega Bases, Chicago, IL, USA), 200 nM FAM-TAMRA probe (Mega Bases, IL, USA), $100 \mathrm{nM}$ Blue 636 (BD 636), 0.05 units platinum Taq DNA polymerase (Gibco/Life Technologies, Grand Island, NY, USA). The thermal cycling conditions included $94^{\circ} \mathrm{C}$ for five minutes, followed by 40 cycles of amplification at $94^{\circ} \mathrm{C}$ for 30 seconds and $60^{\circ} \mathrm{C}$ for one minute for denaturing and annealing-extension, respectively. All samples were amplified in triplicate.

\section{Western blot analysis}

Synovial tissues were homogenized in a $50 \mathrm{ml}$ conical centrifuge tube containing $3 \mathrm{ml}$ of Complete Mini protease inhibitor cocktail homogenization buffer (Roche, Indianapolis, IN, USA). Synovial tissue homogenization was completed on ice using a motorized homogenizer, followed by sonication for 30 seconds. Homogenates were centrifuged at $2000 \times \mathrm{g}$ for 10 minutes, filtered through a $0.45 \mu \mathrm{m}$ pore size filter (Bedpore, Bedford, MA, USA) and stored at $-80^{\circ} \mathrm{C}$ until use. Complete Mini protease inhibitor cocktail $(1 \mathrm{ml})$ was added to one million RA fibroblasts and HMVECs for lysis. The concentration of protein in each synovial tissue and cell lysate was determined using a bicinchoninic acid assay (Pierce, Rockford,
IL, USA), using BSA as the standard. Protein extracts $(25 \mu \mathrm{g})$ were mixed with an equal volume of $2 \times$ Laemmli's sample buffer. Equal amounts of each sample were loaded and run on a $10 \%$ SDS-PAGE gel and transferred to nitrocellulose membranes using a semi-dry transblotting apparatus (Bio-Rad, Richmond, CA, USA). Nitrocellulose membranes were blocked with $5 \%$ nonfat milk in Trisbuffered saline Tween $(20 \mathrm{mM}$ Tris, $137 \mathrm{mM} \mathrm{NaCl}$, $\mathrm{pH} 7.6$, with $0.1 \%$ Tween 20) for 60 minutes at room temperature. Blots were incubated overnight with anti-Tie1 and anti-Tie2 antibodies (R\&D Systems) at 1:5000, in Tris-buffered saline Tween containing 5\% nonfat milk. Blots were washed three times and then incubated in horseradish-peroxidase-conjugated antibody $(1: 10,000$ dilution) for one hour at room temperature. All blots were developed using the enhanced chemiluminesence reagents (Amersham, Piscataway, NJ, USA) as per the manufacturer's instructions. 